\title{
Multiple Components Rapidly Screened from Perilla Leaves Attenuate Asthma Airway Inflammation by Synergistic Targeting on Syk
}

\author{
This article was published in the following Dove Press journal:
} Journal of Inflammation Research

\author{
Hui Yang' \\ Wei Sun ${ }^{2}$ \\ Pei $M a^{1}$ \\ Chunsuo Yao' \\ Yannan Fan' \\ Shuyi $\mathrm{Li}^{\prime}$ \\ Jiqiao Yuan' \\ Ziqian Zhang' \\ Xuyu Li' \\ Mingbao Lin (D) \\ Qi Hou'
}

'State Key Laboratory of Bioactive Substances and Functions of Natural Medicines, Institute of Materia Medica, Chinese Academy of Medical Sciences \& Peking Union Medical College, Beijing, People's Republic of China; ${ }^{2}$ Beijing Friendship Hospital, Capital Medical University, Beijing, People's Republic of China
Correspondence: Mingbao Lin; Qi Hou Tel +86-10-63165192; $+86-|0-63| 65|9|$

Email mingbaolin@imm.cams.cn; houq@imm.ac.cn
Background: Perilla frutescens (L.) Britt., a classic medicinal plant, has been demonstrated to have anti-inflammatory and anti-allergic effects in asthma. Perilla leaves extract (PLE) exerted significant therapeutic effect against allergic asthma inflammation through Syk inhibition. But the active chemical ingredients from PLE are complex and unclear, it is difficult to fully elucidate its pharmacological mechanisms.

Methods: A method was established for rapid screening and characterization of active ingredients from PLE that targeted Syk, with which three potential active ingredients were identified. By using OVA-induced allergic asthma mouse model in vivo, OVAinduced human PBMCs inflammation model and DNP-IgE/BSA-induced RBL-2H3 cells model in vitro, the effects and mechanisms of PLE and its active components were evaluated.

Results: Using Syk-affinity screening method, roseoside (RosS), vicenin-2 (Vic-2) and rosmarinic acid (RosA) were identified from PLE. In vitro, PLE and its ingredients showed significant inhibitory activities against Syk, with their mixture (Mix, prepared by RosS, Vic-2 and RosA in accordance with their ratio in Syk-conjugated beads bound fraction) showing a stronger inhibitory activity. RosS, Vic-2 and RosA also showed significant effects on allergic asthma, and a synergistic effect of Mix was observed. Moreover, treatment with PLE, RosS, Vic-2, RosA, and Mix significantly inhibited the expression and phosphorylation

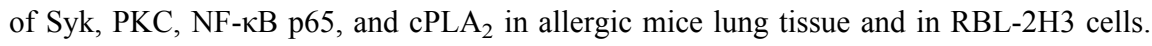

Conclusion: PLE may alleviate allergic airway inflammation partly through the multiple components synergistic targeting on Syk and its downstream inflammatory pathway.

Keywords: allergic airway inflammation, multi-component, PLE, Syk, synergistic effect

\section{Introduction}

Asthma is a heterogeneous disease characterized by chronic and persistent airways inflammation. ${ }^{1}$ Traditional Chinese medicine (TCM) makes fruitful contributions in treating asthma through regulating immune balance and suppressing allergic hyperreactivity. ${ }^{2}$ Perilla frutescens (L.) Britt., an annual herbaceous plant that belongs to the Lamiaceae Mint Family, ${ }^{3}$ has been demonstrated to have antiinflammatory, anti-allergic and immune-regulatory effects in asthma. ${ }^{4}$ However, the active chemical components in Perilla leaves and mechanisms of alleviating asthma airway inflammation are still unknown. Therefore, we aim to develop a method to screen for the bioactive compounds from PLE, and then study their mechanisms of action on asthma. 
The traditional approach applied by researchers in bioactive compound finding is to identify and isolate pure chemically defined active compounds. But there are lots of disadvantages in traditional methods for TCM study due to the complexity and diversity of components, length of time required, high screening cost, large sample demand and extremely easy loss of bioactive trace components. ${ }^{5}$ Moreover, TCM works best with combinatory therapies of multi-component due to their synergistic interactions. ${ }^{6}$ Sometimes an herbal product may be showing better effect than an equivalent dose of a single-isolated active ingredient, and its therapeutic efficacy may come from synergistic or additive actions of multiple bioactive ingredients within the herb. ${ }^{7}$ Multiple bioactive compounds within herbs may target one or more (same or different) protein receptors in the biological network. ${ }^{8}$ Therefore, identifying potential targets of herbal effective extract and establishing screening methods based on protein molecular probe technology may provide a new way for the discovery of bioactive compounds in TCM herbs.

One of crucial mechanisms in allergic asthma is characterized by hyper-production of allergen-specific IgE response to antigens, which binds to high-affinity $\mathrm{Fc}$ receptors of IgE (FceRI) on the surface of mast cells and basophils, causing degranulation and release of mediators of allergic inflammation. ${ }^{9}$ Spleen tyrosine kinase (Syk), a 72-kD cytosolic non-receptor protein tyrosine kinase involved in signal transduction in a variety of cell types, ${ }^{10}$ plays a critical role in FceRI-dependent acute inflammatory responses. ${ }^{11}$ It is reported that Syk expression increases in allergic airways inflammation disease, and inhibition of Syk constitutes a therapeutic option for asthma to prevent airway inflammation and hyperresponsiveness. ${ }^{12}$ Upon the cross-linking of an allergen with FceRI, Syk is recruited and activated by the phosphorylation of immunoreceptor tyrosine-based activation motifs (ITAMs), ${ }^{13}$ leading to inflammatory responses in mast cell and basophils via activating multiple downstream signaling processes, including protein kinase $\mathrm{C}$ (PKC), nuclear factor- $\mathrm{KB}$ (NF- $\mathrm{kB})$ and cytosolic phospholipase A2 $\left(\mathrm{cPLA}_{2}\right){ }^{12,14,15}$ Consequently, Syk is considered as a potentially useful therapeutic target for allergic airway inflammation. Therefore, Syk may be a potential protein molecular probe for bioactive compounds screening from PLE.
Molecular probe technology is an important tool in chemical biology and chemical proteomics. Magnetic beads have been widely used for biological and chemical affinity isolation with the assistance of a magnetic field due to its excellent suspension stability, easy surface modification, and convenient solid-liquid separation. ${ }^{5}$ Carboxyl-modified beads provide an excellent solid support for amide bonding with an enzyme's amino group, ${ }^{16}$ and immobilization of enzymes on beads surface can be used to isolate bioactive components without inhibiting enzymatic activity. ${ }^{17}$ Therefore, Syk-conjugated beads were employed to screen for Syk affinitive compounds from PLE, and HPLC/MS was used for compounds identification and semi-quantification.

In the present study, a method based on Sykconjugated beads coupled with LC/MS was established and used to isolate and identify Syk affinitive compounds from PLE. The anti-allergic inflammatory effects and mechanisms of Syk affinitive compounds were evaluated both in vivo and in vitro. We aim to find bioactive components in PLE for the treatment of asthma, and study the synergistic pharmacodynamics displayed by combination of different bioactive components that affect Syk activity.

\section{Materials and Methods Preparation of PLE ${ }^{18,19}$}

The extract of Perilla frutescens (L.) Britt leaves was prepared as follows. Dried and crushed Perilla frutescens leaves were reflux extracted with 5-fold (w/v) ethanol (70\%) for $1.5 \mathrm{~h}$ twice. The supernatant was filtrated, and the recovered ethanol fraction was concentrated. The extract was mixed with 3 -fold $(\mathrm{w} / \mathrm{v})$ water to make a suspension, which was further extracted with 3-fold water-saturated ethyl acetate twice. The water layer went through precipitation in $80 \%$ ethanol for $24 \mathrm{~h}$, and the ethanol supernatant was subsequently collected, concentrated, and dried to yield PLE.

\section{Screening of Syk Affinitive Components from PLE}

After Dynabeads MyOne Carboxylic Acid (Invitrogen, California, USA) were activated with $50 \mu \mathrm{L}$ EDC $(50 \mathrm{mg} / \mathrm{mL}$ dissolved in MES) and $50 \mu \mathrm{L}$ NHS $(50 \mathrm{mg} /$ $\mathrm{mL}$ dissolved in MES), $60 \mu \mathrm{L}$ Syk $(1 \mathrm{mg} / \mathrm{mL}$ dissolved in MES) and $40 \mu \mathrm{L}$ MES were added to beads and allowed to 
incubate for $16 \mathrm{~h}$ at $4^{\circ} \mathrm{C}$. The beads (Syk targeted) were then washed 3 times with MES, vortexed and incubated with $600 \mu \mathrm{L}$ PLE $(20 \mathrm{mg} / \mathrm{mL})$ for $2 \mathrm{~h}$ at room temperature (RT). Then, the beads were sampled on a MS separation column with a MiniMACS ${ }^{\mathrm{TM}}$ separator (Miltenyi Biotec, Berlin, Germany) and washed with appropriate amount of water 3 times. Individual eluents were collected upon the addition of $600 \mu \mathrm{L}$ of $10 \%, 50 \%$ and $100 \%$ methanol. All the eluents were then concentrated to $600 \mu \mathrm{L}$ volume. Uncoated beads were used as control (Blank).

The Syk affinitive components were characterized and identified by LC-MS/MS (QSTAR Elite LC-MS /MS System, Massachusetts, AB SCIEX, USA). Electrospray ionization was operated in a negative ion mode. EC-C18 column $(4.6 \times 100 \mathrm{~mm}, 2.7 \mu \mathrm{m}$, Agilent, California, USA) was used in reversed-phase mode, and the column temperature throughout the analysis was $30^{\circ} \mathrm{C}$. The injection volume was $20 \mu \mathrm{L}$. The mobile phase (at a flow rate of $1 \mathrm{~mL} / \mathrm{min}$ ) consisted of water with $0.1 \%$ formic acid (A) and acetonitrile (B). The gradient elution was set as follows: 0-15 min, 90-80\% A; 15-30 $\mathrm{min}, 80-60 \%$ A; 30-45 min, 60-40\% A; 45-60 min, 40-0\% A. Fragments were detected within the $\mathrm{m} / \mathrm{z}$ range $100-1000$. The standards of RosS, Vic-2 and RosA were used to confirm identity of compounds analyzed by LC-MS/MS.

\section{Animals}

Male Balb/c mice (6-8 weeks old, 18-20 g, Beijing Vital River Laboratory Animal Technology Co., Ltd., Beijing, China) were raised under pathogen-free conditions with controlled temperature of $24 \pm 2{ }^{\circ} \mathrm{C}$ and humidity of $60 \pm$ $5 \%$ with a $12 \mathrm{~h}$ light/dark cycle. Standard laboratory chow and water were provided ad libitum. All animal experiments were approved from The Animal Care \&Welfare Committee Institute of Meteria Medica, Chinese Academy of Medical Sciences \& Peking Union Medical College (CAMS \& PUMC, Beijing, China) (Permission number: 00000484) and the animal care complied with the guidelines (Standard Operating Procedure for Animal Experimental Center, Institute of Materia Medica, CAMS \& PUMC).

\section{OVA-Induced Asthma Airway Inflammation and Treatment}

Mice were sensitized with intra-peritoneal injection (i. p.) of $30 \mu \mathrm{g}$ OVA (Sigma-aldrich, Missouri, USA) plus
$1 \mathrm{mg}$ aluminum hydroxide gel (Meihua chemical industry limited company, Shanghai, China) in $0.2 \mathrm{~mL}$ normal saline $(0.9 \% \quad \mathrm{NaCl}$, Shijiazhuang No.4 Pharmaceutical, Beijing, China) on days 1, 7 and $14 .^{20,21}$ They were then challenged with intratracheal instillation of $80 \mu \mathrm{g}$ OVA in $50 \mu \mathrm{L}$ normal saline on days 26-28, and then euthanized by cervical dislocation on day 29, in accordance with the requirements of The Animal Care \& Welfare Committee Institute of Meteria Medica, CAMS \& PUMC. The control animals were sensitized and challenged with the same volume of normal saline solution.

Animals were divided into groups randomly. On days 15-28, to study the effects of Syk affinitive components from PLE on asthma inflammation, mice were intragastrically administrated with $200 \mathrm{mg} / \mathrm{kg}$ PLE, $10 \mathrm{mg} / \mathrm{kg}$ RosS, $10 \mathrm{mg} / \mathrm{kg}$ Vic-2, $10 \mathrm{mg} / \mathrm{kg}$ RosA (all from Yuanye BioTechnology Co., Ltd, Shanghai, China), Mix (consisted of $4.047 \mathrm{mg} / \mathrm{kg}$ RosS, $5.798 \mathrm{mg} / \mathrm{kg}$ Vic-2 and $0.155 \mathrm{mg} / \mathrm{kg}$ RosA, with a mass ratio of $40.47 \%$ : $57.98 \%$ : $1.55 \%$ as described in Figure 1E), and $0.5 \mathrm{mg} / \mathrm{kg} \mathrm{Dex}{ }^{22}$ (Sinopharm Group Rongsheng Pharmaceutical Co., Ltd., Shanghai, China). Control and asthma model group were administrated with normal saline.

\section{Measurement of Cell Counts in Bronchoalveolar Lavage Fluid}

Twenty-four hours after the last challenge, mice were anesthetized, and their bronchoalveolar lavage fluid (BALF) was collected by triple intratracheal instillation with $0.7 \mathrm{~mL}$ PBS, followed by centrifugation of the fluid samples at $4^{\circ} \mathrm{C}$. The supernatants were collected and stored at $-80^{\circ} \mathrm{C}$ for enzyme-linked immunosorbent assay (ELISA). The cell pellets were resuspended in $0.5 \mathrm{~mL}$ PBS containing EDTA $2 \mathrm{~K}(5 \mathrm{mg} / \mathrm{mL})$, and the total white blood cells, neutrophils, lymphocytes, monocytes and eosinophils were counted in a hemocytometer (Mindray BC-5000 vet, Shenzhen, China).

\section{Histologic Assessment of Lung Tissue}

Lung tissues from mice were excised, fixed in 10\% formalin solution, embedded in paraffin and cut into $4 \mu \mathrm{m}$ slices, and then stained with hematoxylin-eosin (H\&E) according to standard protocols. The morphometric analysis of inflammatory cell infiltration was performed under light microscopy $(100 \times)$, selecting venules with diameter 

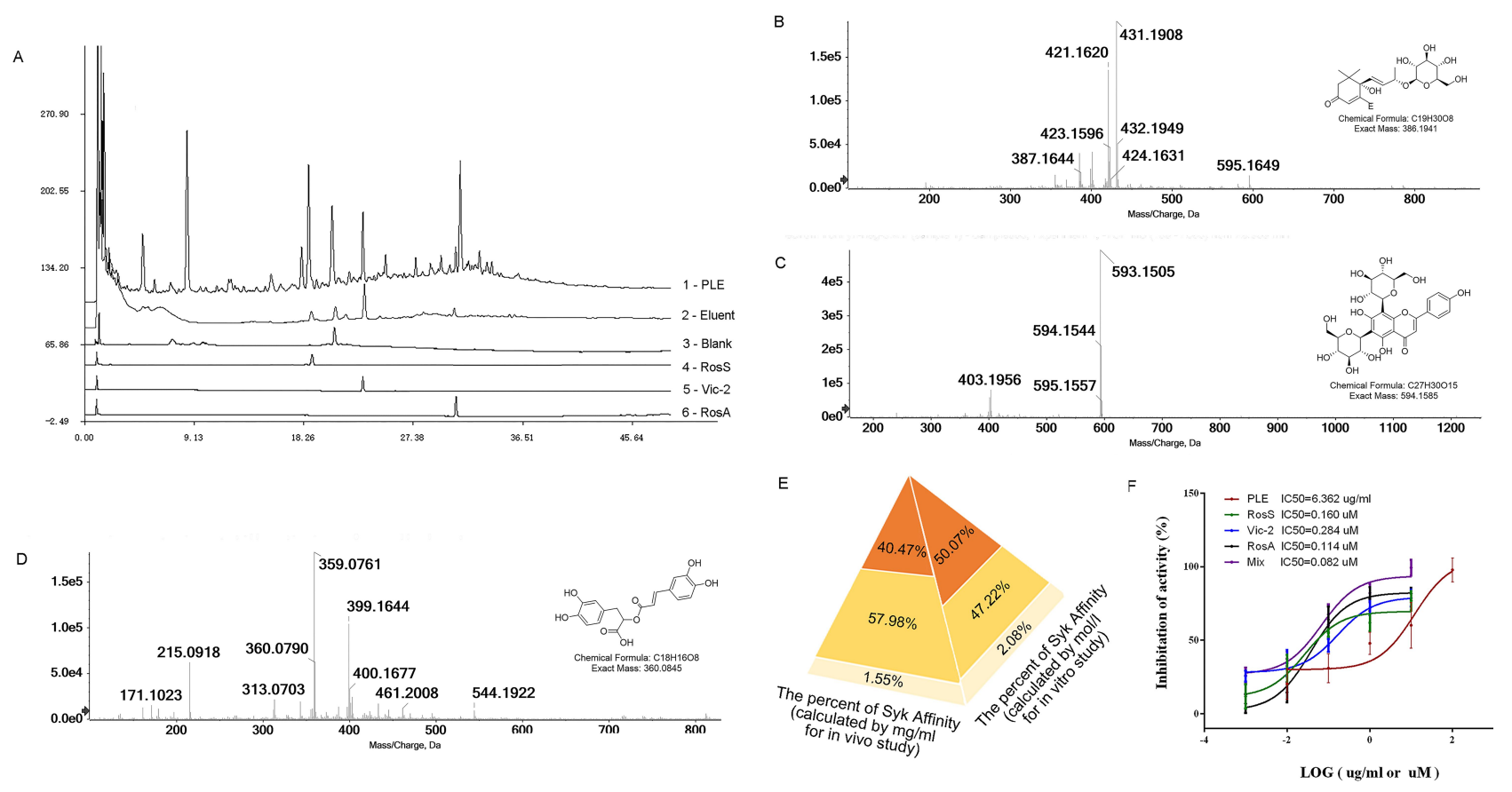

Figure I Extraction and identification of Syk affinitive components from PLE and their inhibited activity on Syk in vitro. (A) HPLC chromatograms: I - PLE, 2 - Eluent, 3 Blank, and 4 - RosS, 5 - Vic-2, and 6 - RosA Standard reference substances. (B) lon chromatograms (EIC) of LC-ESI-IT-TOF-MS extracted analysis of the sample peak at $18.750 \mathrm{~min}$. (C) EIC of LC-ESI-IT-TOF-MS extracted analysis of the sample peak at $23.017 \mathrm{~min}$. (D) EIC of LC-ESI-IT-TOF-MS extracted analysis of the sample peak at 33.300 min. (E) The relative abundance of Syk affinitive compounds as calculated by mass concentration ( $\mathrm{mg} / \mathrm{mL}$ ) and molar concentration (mol/L). (F) In vitro Syk inhibitory activities of PLE, RosS, Vic-2, RosA, and Mix $(n=3)$.

of 100-200 $\mu \mathrm{m}$ and bronchi with diameter of 150-300 $\mu \mathrm{m}$. Typically, five blood vessels or bronchi were selected from each section. A 4-point scoring scale was used: Grade 0, no observable inflammatory cell infiltration; Grade 1, occasional cuff-like inflammatory cell infiltration; Grade 2 , inflammatory cells infiltration in most of the veins/ bronchus and 1-5 layer(s) of inflammatory cells; Grade 3 , obvious inflammatory cells infiltration in most of the veins/bronchus and inflammatory cells greater than 5 layers. The evaluation was performed by an observer who was blind to the group.

\section{Human PBMCs Isolation, Culture, Stimulation and Treatment}

Whole blood sample of healthy volunteers was obtained from Clinical Laboratory Center, Beijing Friendship Hospital with written informed consent. Human PBMCs were isolated by gradient centrifugation of EDTA-anticoagulant-treated peripheral blood samples over Lymphocyte Separation Medium (Haoyang Biological Manufacture Co., Ltd., Tianjin, China) using a Ficoll-Paque method. The collected cells were resuspended in RPMI-1640 supplemented with $10 \%$ FBS at $2.5 \times 10^{5} / \mathrm{mL}$. The cell suspension was aliquoted (0.2 $\mathrm{mL} /$ well) onto a 96-well culture plate. PBMCs were pre-treated with PLE $(50 \mu \mathrm{g} / \mathrm{mL})$, RosS (5 $\mu \mathrm{M})$, Vic-2 (5 $\mu \mathrm{M})$, RosA (5 $\mu \mathrm{M})$ and Mix (consisted of $2.535 \mu \mathrm{M}$ RosS, $2.361 \mu \mathrm{M}$ Vic-2 and $0.104 \mu \mathrm{M}$ RosA, with a molar ratio of $50.70 \%$ : 47.22\%: 2.08\%) for $1 \mathrm{~h}$ at $37^{\circ} \mathrm{C}$. The cells were then stimulated twice with OVA $(0.5 \mu \mathrm{g} / \mathrm{mL})$ after $12 \mathrm{~h}$ and $24 \mathrm{~h}$. The supernatants were then collected to detect the production of inflammatory factors.

The human study had full ethical approval from the Institutional Ethics Committee of Clinical laboratory, Beijing Friendship Hospital (Beijing, China) (Permission number: BFHCC20160110). The written informed consent was acquired from every patient. The study was conducted in line with the guidelines outlined in the Declaration of Helsinki.

\section{RBL-2H3 Cell Culture, Stimulation and Treatment}

Rat basophilic leukemia -2H3 (RBL-2H3) cell line was purchased from National Infrastructure of Cell Line Resource (Beijing, China) and cultured in DMEM medium supplemented with $10 \%$ FBS and $100 \mathrm{U} / \mathrm{mL}$ penicillin and $100 \mu \mathrm{g} / \mathrm{mL}$ streptomycin at $37^{\circ} \mathrm{C}$ in a $5 \% \mathrm{CO}_{2}$ incubator. 
Cells were seeded at $4 \times 10^{4}$ cells per well onto 96 -well plates for TNF- $\alpha$ determination, $8 \times 10^{4}$ cells per well on 48-well plates for $\beta$-hexosaminidase $(\beta$-Hex), toluidine blue and immunofluorescence detection, and $2 \times 10^{6}$ cells in culture dishes for Western blotting (WB) analysis. The plated cells were sensitized with $50 \mathrm{ng} / \mathrm{mL}$ anti-DNP IgE (Sigma-aldrich) for $12 \mathrm{~h}$, before being pretreated with PLE $(50 \mu \mathrm{g} / \mathrm{mL}), \operatorname{RosS}(5 \mu \mathrm{M})$, Vic-2 $(5 \mu \mathrm{M})$, RosA $(5 \mu \mathrm{M})$ and Mix (consisted of $2.535 \mu \mathrm{M}$ RosS, $2.361 \mu \mathrm{M}$ Vic-2 and $0.104 \mu \mathrm{M}$ RosA, with a molar ratio of $50.70 \%$ : 47.22\%: 2.08\%), or with Mix, Syk inhibitor (BAY613606, $0.05 \mu \mathrm{M}$ ), PKC inhibitor (Rottlerin, $1 \mu \mathrm{M}$ ), NF- $\kappa \mathrm{B}$ inhibitor (BAY11-7082, $2 \mu \mathrm{M}$ ) and $\mathrm{cPLA}_{2}$ inhibitor (Arachidonyl trifluoromethyl ketone, ATK, $1 \mu \mathrm{M}$ ) for 1 $\mathrm{h}$, and control cells were cultured under normal conditions with vehicle. Then, the cells were stimulated with $25 \mathrm{ng} /$ mL DNP-BSA (Biosearch, California, USA) in PIPES buffer for $45 \mathrm{~min}$, cell culture supernatants were collected for $\beta$-Hex detection and cells were used for toluidine blue staining. Or the cells were stimulated with $25 \mathrm{ng} / \mathrm{mL}$ DNPBSA in complete DMEM medium for $12 \mathrm{~h}$ (cell culture supernatants were collected for TNF- $\alpha$ test) or $4 \mathrm{~h}$ (cells were used for immunofluorescence staining and WB analysis).

\section{$\beta$-Hexosaminidase Secretion Assay}

After DNP-BSA stimulation, $50 \mu \mathrm{L}$ cell supernatant and $50 \mu \mathrm{L} 2 \mathrm{mM}$ p-nitrophenyl-N-acetyl- $\beta$-D-glucosaminide (Sigma-aldrich) in $100 \mathrm{mM}$ citrate buffer (pH 4.5) were incubated for $1 \mathrm{~h}$ at $37^{\circ} \mathrm{C}$. Afterwards, $200 \mu \mathrm{L}$ carbonate buffer $\left(0.1 \mathrm{mM} \mathrm{NaHCO} / \mathrm{Na}_{2} \mathrm{CO}_{3}, \mathrm{pH} 10.0\right)$ was added to stop the reaction. The absorbance was measured with a microplate reader (Power Wave XS2, BioTek, Virginia, USA) at $405 \mathrm{~nm}$. The data were expressed as the percent release of $\beta$-Hex (\%), $\beta$-Hex release $(\%)=\mathrm{T} / \mathrm{A} \times 100 \%$. A represents the average OD value of the model group, $\mathrm{T}$ represents the OD value of each test well.

\section{Toluidine Blue Stain}

Treated cells were washed twice with PBS, fixed with paraformaldehyde for $20 \mathrm{~min}$ and then stained with $0.5 \%$ toluidine blue for $10 \mathrm{~min}$. Images were subsequently captured with an Inverted Research Microscope (Nikon Eclipse Ti2, Tokyo, Japan), and the data were expressed as the percent of degranulation (\%), which equaled to the number of degranulated cells/the number of total cells.

\section{Immunofluorescence Staining}

RBL-2H3 cells in 48-well plates were washed, fixed with $4 \%$ paraformaldehyde for $20 \mathrm{~min}$, incubated sequentially with $0.5 \%$ triton $\mathrm{X}-100$ for $20 \mathrm{~min}$ and then blocked with $3 \%$ goat serum for $30 \mathrm{~min}$. Next, cells were incubated with anti-p-Syk and anti-Syk antibodies separately overnight at $4^{\circ} \mathrm{C}$. Cells were subsequently incubated with Alexa Fluor 546 conjugated secondary antibody at RT for $2 \mathrm{~h}$, and nuclei were stained with DAPI for $10 \mathrm{~min}$. Three different fields from each well were imaged with an Inverted Research Microscope, and the mean fluorescence intensity was calculated by comparing the average pixel intensity of the red fluorescence with average pixel intensity of the blue fluorescence inside the nuclear region.

\section{Determination of Cytokines by ELISA}

The concentrations of multiple cytokines (TNF- $\alpha$, IL-6, IL-8, IL-4 and IFN- $\gamma$ ) in BALF or culture supernatants from RBL-2H3 cells and PBMCs, and the levels of IgE, $\operatorname{IgG1}, \operatorname{IgG} 2 \mathrm{a}$ and $\operatorname{IgG} 2 \mathrm{~b}$ in serum were determined by ELISA kits (Biolegend, California, USA) according to their respective protocols.

\section{Western Blotting (WB) Analysis}

Protein samples were extracted from lung tissues and cells. Equal amounts of protein were analyzed by $10 \%$ sodium dodecyl sulfate-polyacrylamide gel electrophoresis and transferred onto polyvinylidene difluoride membranes (Millipore, Bedford, MA, USA). The membranes were first probed with specific primary antibodies against Syk, phospho-Syk (Y525/526), PKC, phospho-PKC, NF-kB p65, phospho-NF-кB p65 (Ser536), cPLA 2 and phosphocPLA $_{2}$ (Ser505) (Cell Signal Technology, Massachusetts, USA) separately at $4^{\circ} \mathrm{C}$ overnight. $\beta$-actin (Cell Signal Technology) was used as a loading control. Horseradish peroxidase-conjugated anti-rabbit secondary antibodies were used and visualized using the enhanced chemiluminescence kit (Thermo Scientific, Massachusetts, USA). Digital images were subsequently captured with a Chemical imaging system (Clinx Science Instruments Co., Ltd, China) and Image-J software (National Institutes of Health, Maryland, USA) was used for densitometric analysis. 


\section{In vitro Syk Inhibitory Assay}

The experiments were carried out according to manufacturer's instructions on Syk Kinase Enzyme System (Promega, Wisconsin, USA) and ADP-Glo ${ }^{\mathrm{TM}}$ Kinase Assay (Promega). Two $\mu \mathrm{L}$ Syk $(2 \mathrm{ng} / \mu \mathrm{L}), 2 \mu \mathrm{L}$ substrate (Poly E4Y1, $0.2 \mu \mathrm{g} / \mu \mathrm{L}$ ), adenosine triphosphate (ATP, $10 \mu \mathrm{M}$ ) mixture, and $1 \mu \mathrm{L}$ test samples were added to each well of a 384-well plate. After incubation at RT for $30 \mathrm{~min}, 5 \mu \mathrm{L}$ adenosine diphosphate(ADP-) Glo $^{\mathrm{TM}}$ reagent was added to each well and incubated at RT for $40 \mathrm{~min}$. And then $10 \mu \mathrm{L}$ kinase detection reagent was added and incubated at RT for an additional $30 \mathrm{~min}$. Finally, chemiluminescent signal was recorded using a SYNERGY H1 microplate reader (BioTek, Winooski, VT, USA).

\section{Statistical Analysis}

Data were expressed as mean \pm standard error (SEM). As the normality test by Kolmogorov-Smirnov test (K-S test) was passed, data were analyzed by using the Student's $t$-test for comparison between two groups and one-way ANOVA for multiple groups followed by Fisher's least significant difference (LSD) test, otherwise, by using Kruskal-Wallis $H$-test. Statistical significance was set at $\mathrm{P}<0.05$ or $\mathrm{P}<0.01$. The above analyses were conducted with GraphPad Prim 6.0 and IBM SPSS 19.0 statistical software.

\section{Results}

\section{Screening Syk Affinitive Components} from PLE and Detecting Their Inhibitory Activity on Syk

In order to extract potential Syk affinitive compounds from PLE, a rapid screening method was developed by using Syk-conjugated beads coupled to LC/MS. Compared to the HPLC chromatograms of PLE (Figure 1A1) and Blank (Figure 1A3), three major peaks (with retention times about $18.750 \mathrm{~min}, 23.017$ min and $33.300 \mathrm{~min}$ ) were found with the Sykconjugated beads eluent (Figure 1A2). After further analysis with molecular ion information and fragmentation features on LC-MS/MS spectra, and checking with standard compounds, the identity of the three major Syk affinitive peaks were identified as RosS (Figure 1B), Vic-2 (Figure 1C) and RosA (Figure 1D), respectively. The concentrations of RosS, Vic-2 and RosA in PLE were $0.0417 \mathrm{mg} / \mathrm{mL}, 0.0277 \mathrm{mg} / \mathrm{mL}$ and $0.0434 \mathrm{mg} / \mathrm{mL}$, which in Syk-conjugated beads eluent were $0.0095 \mathrm{mg} / \mathrm{mL}, 0.0136 \mathrm{mg} / \mathrm{mL}$ and $0.0004 \mathrm{mg} / \mathrm{mL}$ calculated by their peak areas. Based on the relative abundance of these 3 compounds in the Syk-conjugated beads eluent, a mixture of these 3 compounds (designated as Mix, Figure 1E) was prepared either by mass concentration $(\mathrm{mg} / \mathrm{mL}, 40.47 \%$ : $57.98 \%: 1.55 \%$ calculated by their peak areas, used for in vivo experiments) or by molar concentration (mol/L, 50.70\%: 47.22\%: $2.08 \%$ calculated by their peak areas and molar mass, used for in vitro experiments), respectively. In addition, the effect of PLE, RosS, Vic-2, RosA and Mix (mixture of RosS, Vic-2 and RosA) in inhibiting Syk kinase activity was determined in vitro. PLE, RosS, Vic-2 and RosA exhibited Syk inhibitory activity in vitro with $\mathrm{IC}_{50}$ values of $6.362 \mu \mathrm{g} / \mathrm{mL}$, $0.160 \mu \mathrm{M}, 0.284 \mu \mathrm{M}$ and $0.114 \mu \mathrm{M}$, respectively (Figure 1F). Notably, compared with individual affinity compound, Mix showed a much higher inhibitory activity with an $\mathrm{IC}_{50}$ value of $0.082 \mu \mathrm{M}$.

\section{Syk Affinitive Components from PLE Attenuated Allergic Airway Inflammation}

\section{in vivo}

In order to verify that Syk affinitive compounds (RosS, Vic-2, and RosA) were important active components of PLE, their effects on allergic airway inflammation were further evaluated on OVA-induced asthma mice in vivo.

PLE, RosS and Vic-2 treatment significantly attenuated OVA-induced infiltration of inflammatory cells into lung tissue ( $\mathrm{P}<0.05$ or 0.01 ), and Mix treatment exhibited a more significant reversal of lung histologic changes (Figure 2A and B). Except RosS and Vic-2 effectively reduced the number of neutrophils and eosinophils in BALF of allergic mice, RosS, Vic-2 and RosA treatment did not seem to affect the number of total and differential leukocytes in BALF of allergic mice (Figure 2C). On the other hand, Mix treatment showed a marked decrease in them $(\mathrm{P}<0.01)$. Furthermore, RosS, Vic-2 and RosA treatment significantly decreased the levels of IL-6 (Figure 2D), TNF- $\alpha$ (Figure 2E), IL-4 (Figure 2F) and the ratio of IL-4/IFN- $\gamma$ (Figure 2G) in BALF, and an enhancement effect of Mix was observed. Consistently, Mix also showed a stronger inhibitory activity in the level of $\operatorname{IgE}$ 


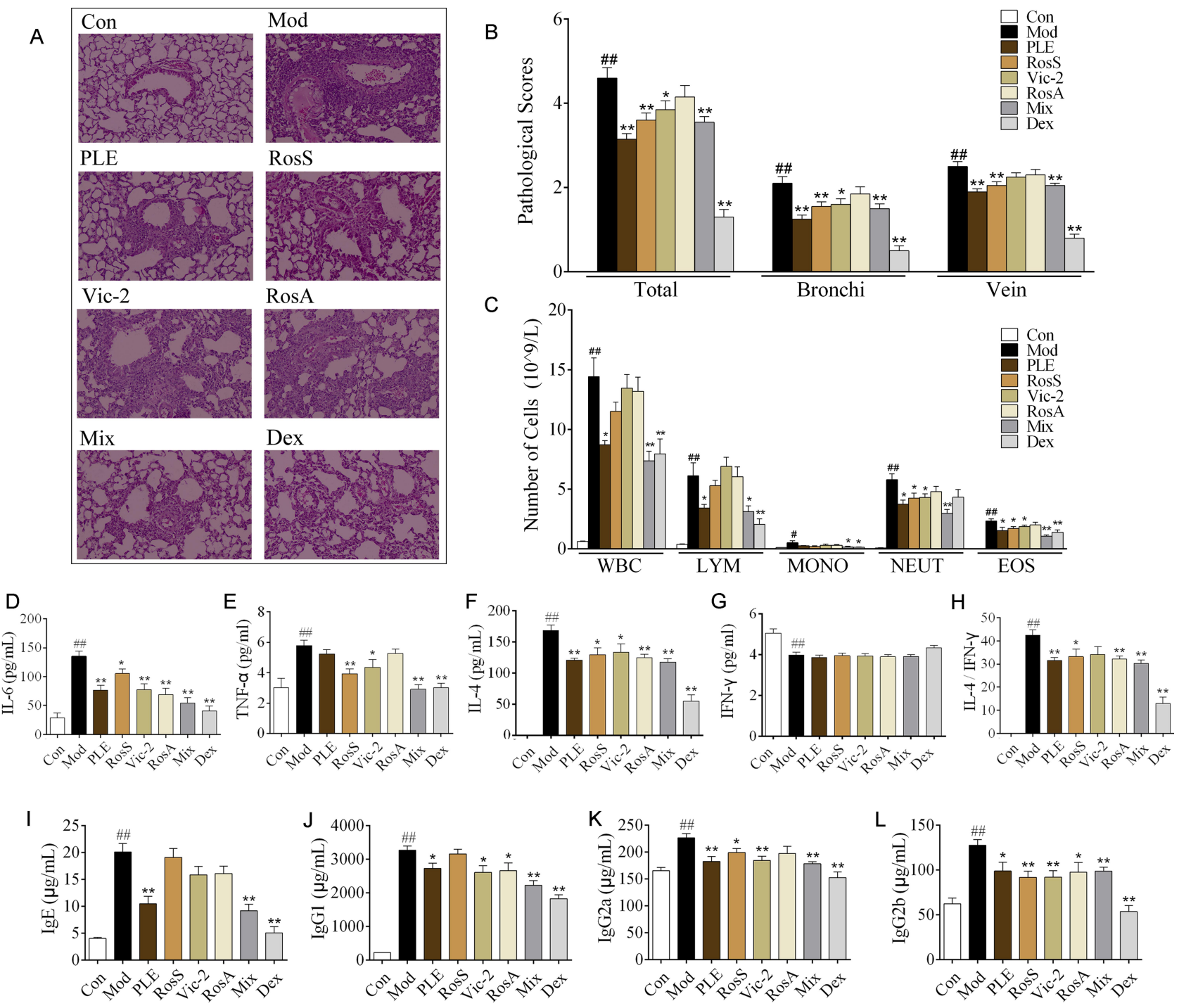

Figure 2 Effects of Syk affinitive compounds from PLE on allergic airway inflammation in vivo. (A) Pathological changes in lung tissue were determined by H\&E staining (magnified $\times 100$ ). (B) The scoring of inflammatory cells infiltration in H\&E stained lung tissues ( $\mathrm{n}=20$ was carried out using independent slices from 4 mice in each group). (C) Total and differential leukocyte counts in BALF $(n=8)$. (D-H) The levels of IL-6, TNF- $\alpha$, IL-4, IFN- $\gamma$ and the ratio of IL-4/IFN- $\gamma$ in BALF ( $n=8)$. (I-L) The levels of IgE, $\operatorname{lgGI}$, IgG2a and IgG2b in serum $(n=8)$. Data were shown as mean \pm SEM; ${ }^{\prime} P<0.01$ vs control group; $* P<0.05$ and $* * P<0.01$ vs model group.

(Figure 2I), IgG1 (Figure 2J), IgG2a (Figure 2K) and IgG2b (Figure $2 \mathrm{~L})$ in serum $(\mathrm{P}<0.05$ or 0.01$)$.

\section{Syk Affinitive Components from PLE} Attenuated Allergic Airway Inflammation in vitro

OVA-induced human PBMCs and DNP-IgE/BSA-induced RBL-2H3 cells were used to analyze the anti-inflammatory effects of Syk affinitive components from PLE in vitro. The results showed that PLE, RosS, Vic-2 and RosA treatment significantly suppressed the production of IL-6 (Figure 3A) and IL-8 (Figure 3B) in OVA-induced human PBMCs, and considerably inhibited the production of
TNF- $\alpha$ (Figure 3C), the release of $\beta$-Hex (Figure 3D) and the degranulation (Figure 3E) in DNP-IgE/BSAinduced RBL-2H3 cells $(\mathrm{P}<0.05$ or 0.01$)$. Importantly, a synergistic suppression was also observed with the Mix treatment.

\section{Syk Affinitive Components from PLE} Decreased the Expression and Phosphorylation of Syk and Its Downstream Signaling Proteins in vivo

Notable increases of Syk, p-Syk, PKC, p-PKC, NF- $\kappa$, $\mathrm{p}-\mathrm{NF}-\kappa \mathrm{B}, \quad \mathrm{PPLA}_{2}$ and $\mathrm{p}-\mathrm{cPLA}_{2}$ expression were 

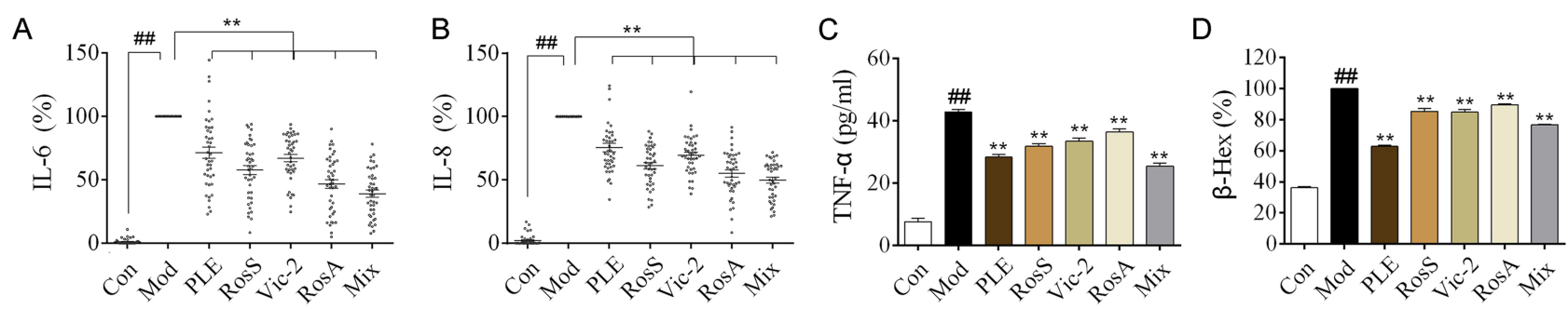

$\mathrm{E}$
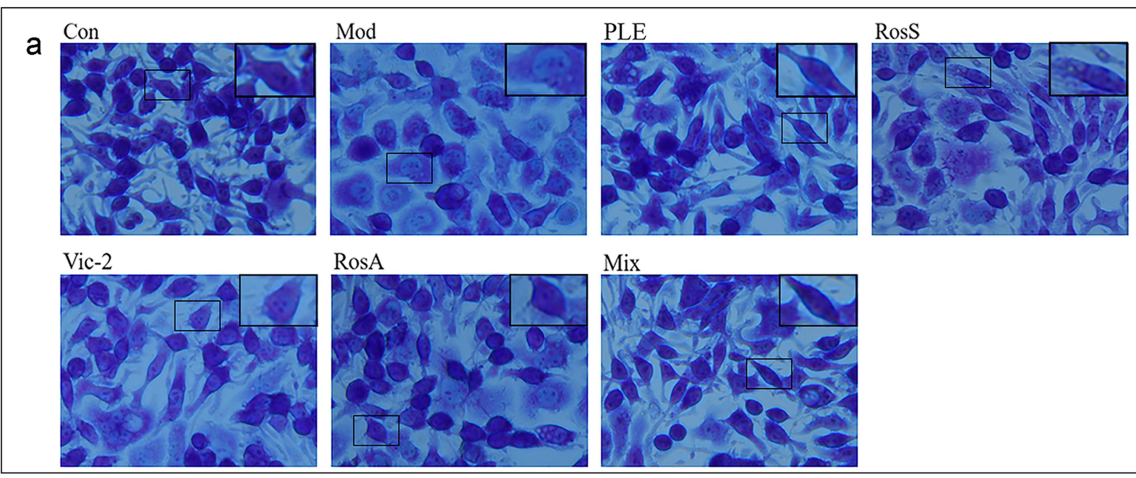

b

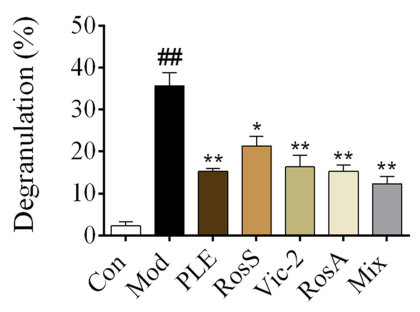

Figure 3 Effects of Syk affinitive compounds from PLE on allergic airway inflammation in vitro. (A, B) The levels of IL-6 and IL-8 in OVA-induced human PBMCs ( $n=42)$. (C) The level of TNF- $\alpha$ in DNP-IgE/BSA-induced RBL-2H3 cells $(n=3$ independent experiments). (D) The release rate of $\beta$-Hex $(\%)$ in DNP-lgE/BSA-induced RBL-2H3 cells $(n=$ 3 independent experiments). (E) (a) Images of DNP-IgE/BSA-induced RBL-2H3 cells stained by toluidine blue staining (magnified $\times 400)$ with (b) its degranulation rate (\%) (n = 3). Data were shown as mean \pm SEM; ${ }^{\# \#} \mathrm{P}<0.01$ vs control group; $* \mathrm{P}<0.05$ and $* * \mathrm{P}<0.01$ vs model group.
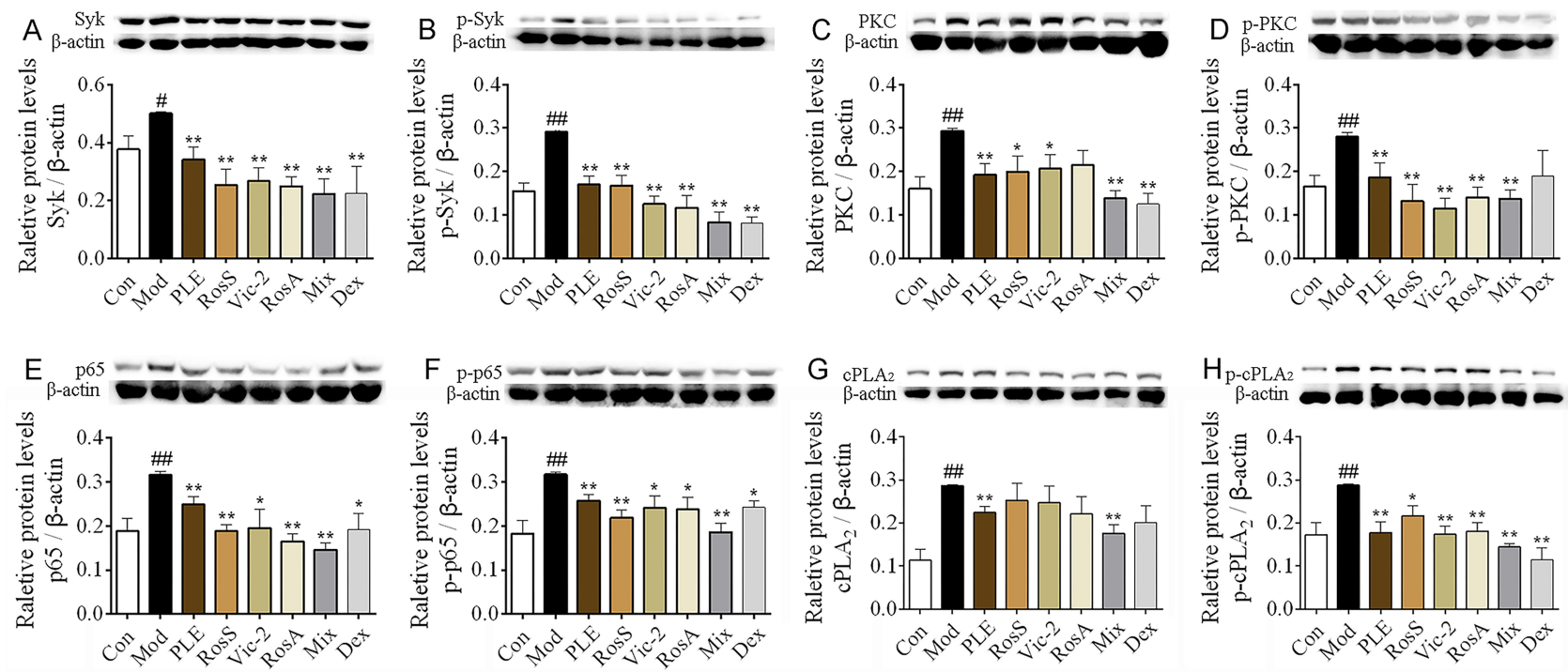

Figure 4 Syk affinitive components from PLE decreased the expression and phosphorylation of Syk and its downstream signaling proteins in vivo. (A-H) The expression of Syk, p-Syk, PKC, p-PKC, p65, p-p65, cPLA 2 , and p-cPLA ${ }_{2}$ in lung tissues of OVA-induced asthmatic mice were determined by WB ( $n=5$ ). Data were shown as mean \pm SEM. ${ }^{\#} \mathrm{P}<0.05$ and ${ }^{\# \#} \mathrm{P}<0.01$ vs control group, ${ }^{*} \mathrm{P}<0.05$ and $* * \mathrm{P}<0.01$ vs model group.

observed in lung tissues of OVA-induced asthma mice $(\mathrm{P}<0.05$ or 0.01 , Figure $4 \mathrm{~A}-\mathrm{H})$, while these alterations, exception of $\mathrm{cPLA}_{2}$, were significantly inhibited with RosS, Vic-2 and RosA treatment. Importantly, with the Mix treatment, the inhibitory effects on these proteins were significantly enhanced, including $\mathrm{cPLA}_{2}$ $(\mathrm{P}<0.01)$.
Syk Affinitive Components from PLE Decreased the Expression and Phosphorylation of Syk and Its Downstream Signaling Proteins in vitro In vitro, the expression of Syk (Figure 5A) and p-Syk (Figure 5B) in DNP-IgE/BSA-induced RBL-2H3 cells 

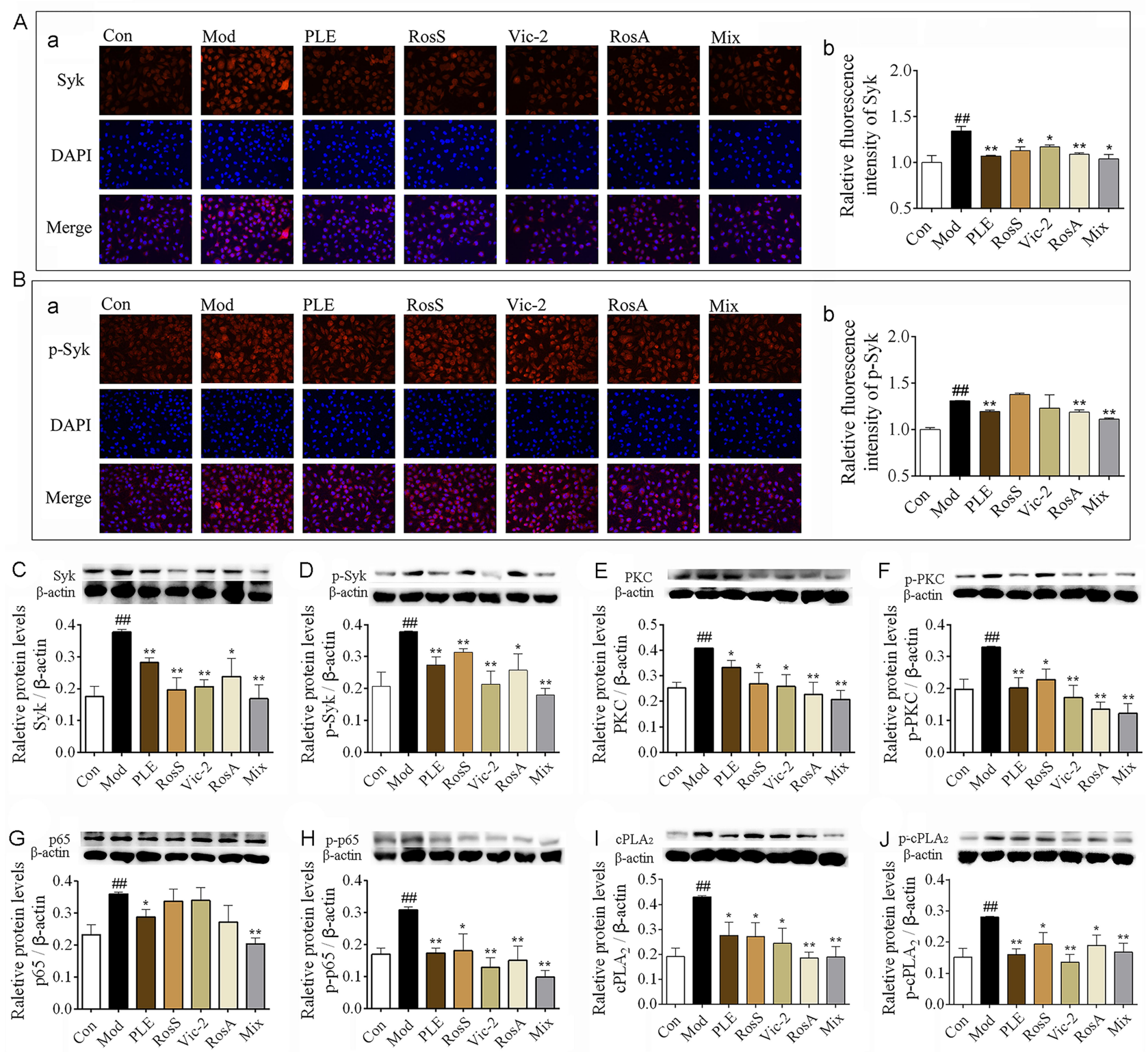

Figure 5 Syk affinitive components from PLE decreased the expression and phosphorylation of Syk and its downstream signaling proteins in vitro. (A) The expression of Syk were determined by immunofluorescence staining, (a) representative photomicrographs $(\times 200)$ of Syk in RBL-2H3 cells and $(b)$ their relative fluorescence intensities $(n=3)$. (B) The expression of p-Syk were determined by immunofluorescence staining, (a) representative photomicrographs $(\times 200)$ of Syk in RBL-2H3 cells and (b) their relative fluorescence intensities $(n=3)$. (C-J) The expression of Syk, p-Syk, PKC, p-PKC, p65, p-p65, cPLA 2 , and p-cPLA 2 in DNP-lgE/BSA-induced RBL-2H3 cells as determined by $W B(n=5)$. Data were shown as mean \pm SEM. ${ }^{\#} P<0.01$ vs control group, ${ }^{*} P<0.05$ and $* * P<0.01$ vs model group.

was significantly reduced with RosS, Vic-2, RosA and Mix treatment determined by immunofluorescence analysis, as consistent with WB (Figure 5C and D). Furthermore, treatment with RosS, Vic-2, RosA significantly inhibited the expression of PKC (Figure 5E), p-PKC (Figure 5F), p-p65 (Figure 5H), cPLA 2 (Figure 5I), and p-cPLA ${ }_{2}$ (Figure 5J) in DNP-IgE/BSA-induced RBL-2H3 cells (P $<0.05$ or 0.01 ). Mix treatment showed a much greater reduction in the expression of these proteins, including the expression of p65 (Figure 5G).

\section{Syk Affinitive Components in PLE} Attenuated Allergic Inflammation by

\section{Targeting on Syk}

To determine whether Syk affinitive components (Mix) in PLE attenuated allergic inflammation by targeting on Syk, Syk inhibitor (BAY61-3606) and inhibitors of Syk's downstream effectors PKC (Rottlerin), NF- $\kappa B$ (BAY11-7082) and $\mathrm{cPLA}_{2}$ (ATK) were utilized for in vitro studies. In accordance with PLE, co-treatment of Mix with Syk inhibitor further 

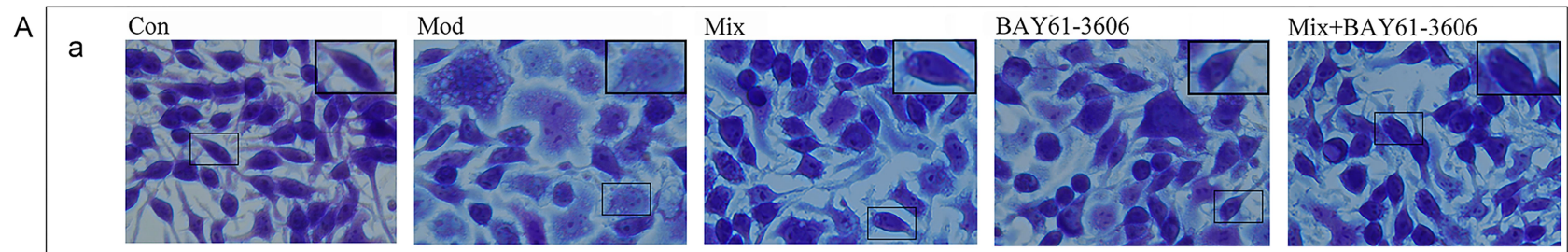

b

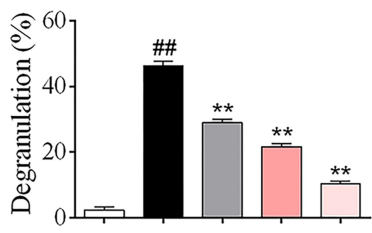

DNP-IgE :

DNP-BSA :

Mix :

BAY61-3606 :

C

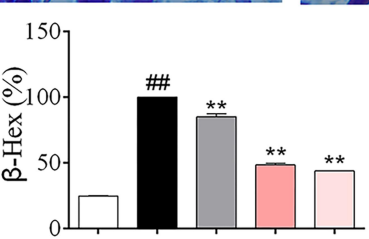

d

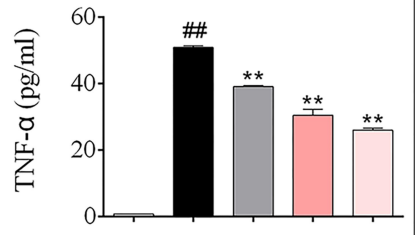

DNP-IgE : DNP-BSA : Mix : BAY61-3606 :

$\begin{array}{lllll}- & + & + & + & + \\ - & + & + & + & + \\ - & - & + & - & + \\ - & - & - & + & +\end{array}$

DNP-IgE : DNP-BSA Mix : BAY61-3606 : -

c

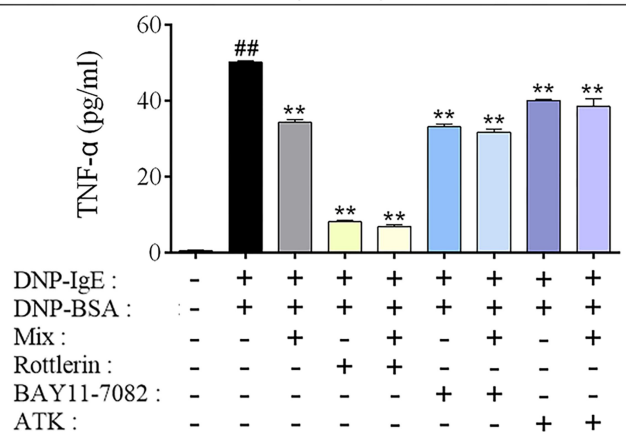

Figure 6 Verification that Syk, PKC, NF- $k B$ and cPLA 2 were associated with Mix attenuated Inflammation in DNP-IgE/BSA-induced RBL-2H3 cells. (A) (a) Images of DNPIgE/BSA-induced RBL-2H3 cells stained by toluidine blue (magnified $\times 400)$, (b) the percent of degranulation (\%) calculated ( $n=3$ ), (c) the release rate of $\beta$-Hex (\%) and (d) the level of TNF- $\alpha$ in cells co-treated Syk affinitive compounds with Syk inhibitor ( $n=3$ independent experiments). (B) The release rate of $\beta$-Hex and (C) production of TNF- $\alpha$ in cells co-treated Syk affinitive compounds with PKC, NF- $-\mathrm{B}$ or $\mathrm{cPLA}_{2}$ inhibitors ( $\mathrm{n}=3$ independent experiments). Data were shown as mean \pm SEM. ${ }^{\#} \mathrm{P}<0.0 \mathrm{I}$ vs control group; $* * \mathrm{P}<0.01$ vs model group.

reduced DNP-IgE/BSA-induced RBL-2H3 cell degranulation and TNF- $\alpha$ production, compared to their individual treatment (Figure 6A). By co-treating Mix with PKC, NF- $\mathrm{kB}$ and cPLA 2 inhibitors, synergistic inhibitory effects of $\beta$-Hex (Figure 6B) and TNF- $\alpha$ (Figure 6C) were also observed.

Additionally, co-treatment of Mix with Syk inhibitor further inhibited the expression of Syk (Figure 7A and B) and p-Syk (Figure 7C and D) determined by immunofluorescence staining and confirmed by WB determination. Interestingly, Mix co-treating with Syk inhibitor decreased the expression and phosphorylation of PKC (Figure 7E and

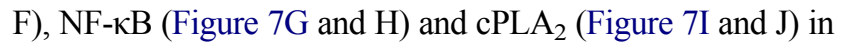
a synergistic manner in according to PLE treatment. While exception of PKC inhibitor, $\mathrm{CPLA}_{2}$ and NF- $\mathrm{KB}$ inhibitors did not affect the expression of Syk and p-Syk (Figure 7K). Collectively, these results suggested that Syk affinitive components were the main active ingredients of PLE which could synergistically attenuate allergic inflammatory response by targeting on Syk, and then regulating $\mathrm{PKC}, \mathrm{NF}-\mathrm{\kappa B}$ and cPLA $_{2}$ expressions.

\section{Discussion}

PLE could suppress Th2 responses and allergic airway inflammation. Because of the complexity and diversity of compounds in PLE, the exact mechanism by which PLE alleviates asthma airway inflammation is difficult to define. Traditionally, isolating and identifying of pure chemically defined active components from plant or TCM is the most common approach for bioactive compound finding. But there are lots of disadvantages, including being time consuming, high screening cost, large sample demand, and extremely easy loss of bioactive trace components. ${ }^{5}$ Moreover, the synergistic mechanism of multi-compound of herbal medicine or natural product could not be clarified through the approach even if single compound may successfully work on specific target. ${ }^{17}$

In the past decades, protein-compound interaction has been found to be essential for pharmacological action and the effects output in vivo. ${ }^{23}$ Protein/enzyme coated magnetic beads, a molecular probe for affinity selection, has 


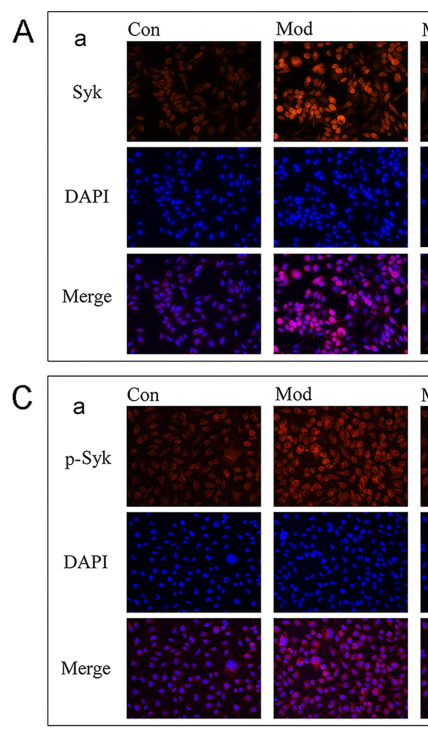

E
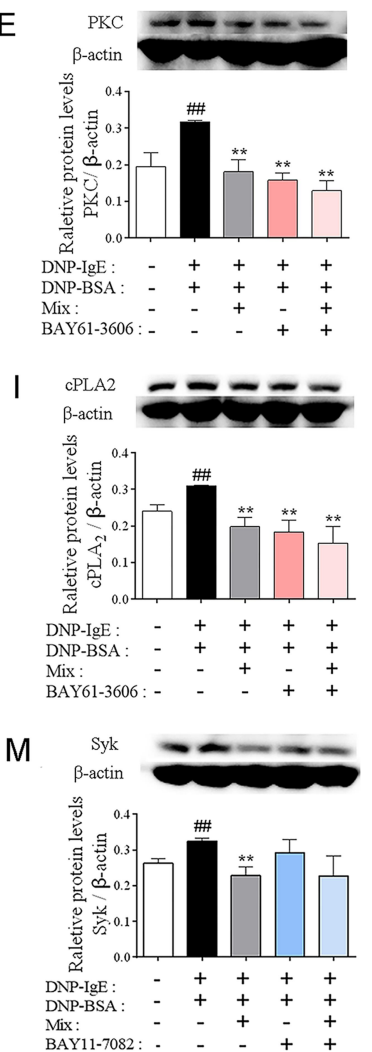
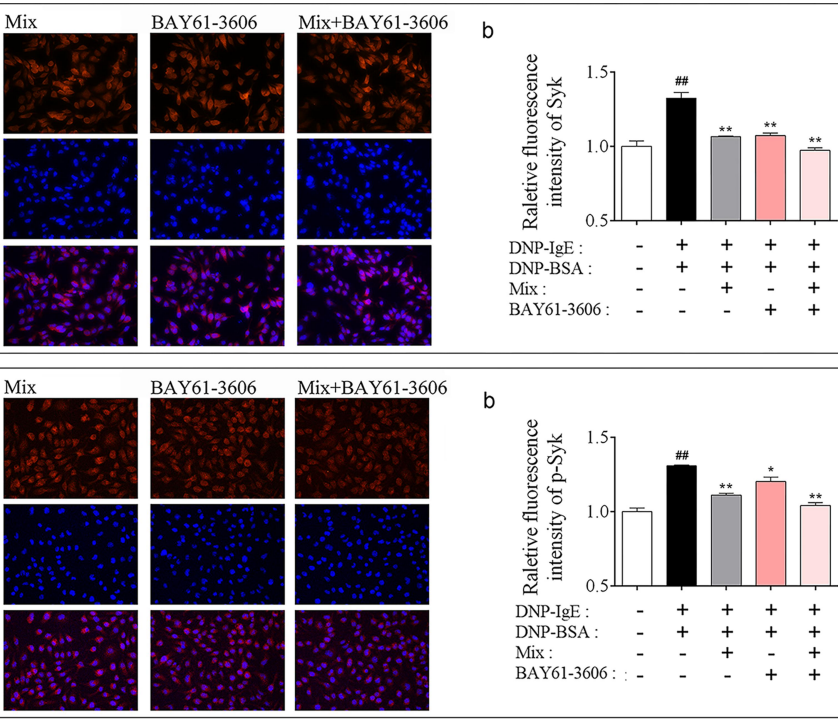

F p-PKC
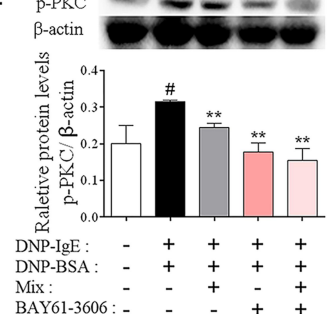

BAY61-3

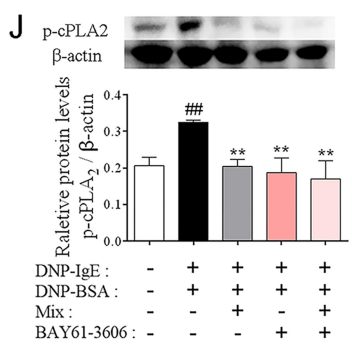

N

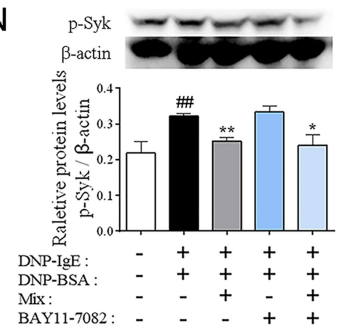

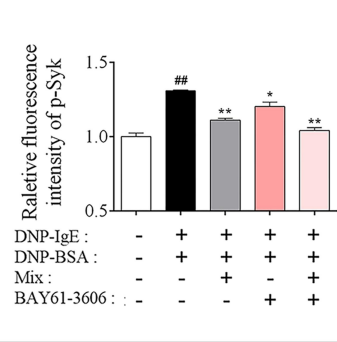

G

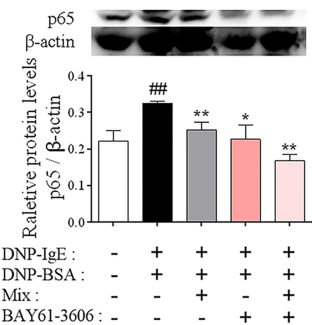

K

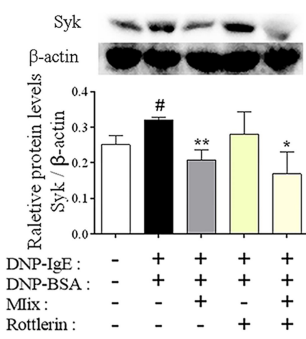

O

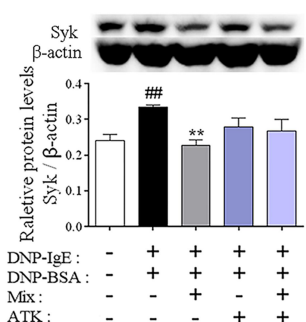

B

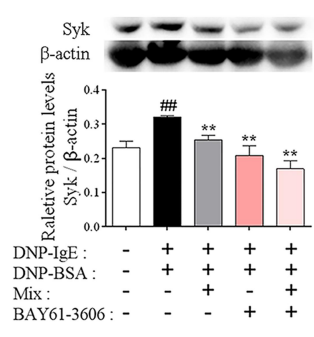

D

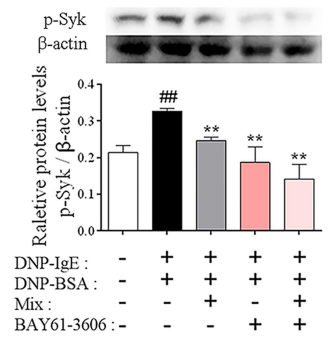

$\mathrm{H}$

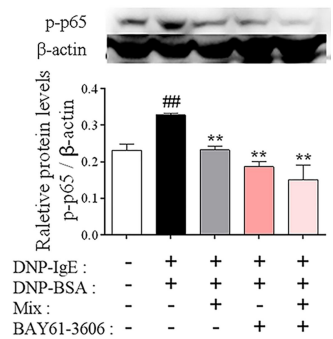

L

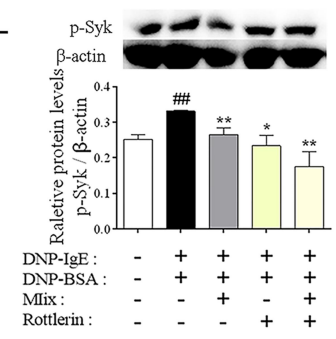

P

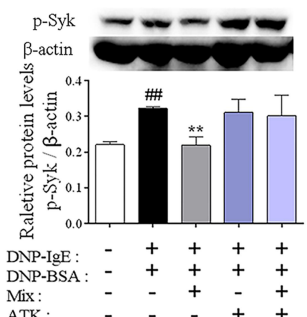

Figure 7 Syk affinitive compounds in PLE attenuated allergic inflammation by synergistically targeting on Syk in DNP-lgE/BSA-induced RBL-2H3 cell. (A) (a) Representative photomicrographs $(\times 200)$ of Syk expression in RBL-2H3 cells and $(b)$ their relative fluorescence intensities as determined by immunofluorescence staining $(n=3)$. (B) The expression of Syk in DNP-lgE/BSA-induced RBL-2H3 cells with Mix of Syk affinitive compounds co-treated with Syk inhibitor detected by WB ( $\mathrm{n}=5$ ). $(\mathbf{C})$ (a) Representative photomicrographs of $(\times 200)$ p-Syk in RBL-2H3 cells and (b) their relative fluorescence intensities as determined by immunofluorescence staining ( $n=3$ ). (D) The expression of $p$-Syk in DNP-IgE/BSA-induced RBL-2H3 cells with Mix of Syk affinitive compounds co-treated with Syk inhibitor detected by WB ( $\mathrm{n}=5$ ). (E-J) The expression of PKC, P-PKC, p65, p-p65, cPLA ${ }_{2}$, and p-cPLA 2 in DNP-IgE/BSA-induced RBL-2H3 cells with Mix of Syk affinitive compounds treatment with the Syk inhibitor detected by WB (n $=5)$. (K-P) The expression of Syk and P-Syk in DNP-lgE/BSA-induced RBL-2H3 cells with Mix of Syk affinitive compounds co-treated with PKC, NF- $k B$ and cPLA 2 inhibitors detected by WB $(n=5)$. Data were shown as mean \pm SEM. ${ }^{\# \#} \mathrm{P}<0.01$ vs control group; ${ }^{*} \mathrm{P}<0.05$ and $* * \mathrm{P}<0.0 \mathrm{I}$ vs model group.

been used to identify active compounds from herbal extract. $^{24}$ With this technique, active compounds and even low-affinity compounds in plant extract are possible to bind directly to the target immobilized onto the surface of beads. ${ }^{25}$ Therefore, in this study, a rapid extraction method using Syk-conjugated beads was established for isolating Syk affinitive compounds in PLE, followed by identification via LC-MS/MS. Using this method, three 
Syk affinitive compounds (RosS, Vic-2 and RosA) were identified. It has been reported that Vic-2 is a potential anti-inflammatory compound ${ }^{26}$ and RosA has antiinflammation effect in a murine model of asthma. ${ }^{27}$

Then, we explored the potential activity of the three compounds and synergistic effect of them on Syk-related inflammatory diseases in vitro and in vivo. Pharmacodynamic synergy means two or more agents that work on the same target and cause enhanced therapeutic effect through their positive interaction. Synergy has been explained from a dose-oriented perspective (reaching the same therapeutic activity but with a lower dose level required), or from an effect-oriented perspective (leading to better therapeutic outcomes at the same dosage level). ${ }^{7}$ In the work, RosS, Vic-2 and RosA were subsequently shown to possess significant Syk inhibitory activities in vitro with $\mathrm{IC}_{50}$ of $0.160,0.284$ and $0.114 \mu \mathrm{M}$, respectively. Mix (consists of lower dose of RosS, Vic-2 and RosA, formulated according to their abundance in Syk affinitive fraction) was shown to further enhance Syk inhibitory activity (with $\mathrm{IC}_{50} 0.082 \mu \mathrm{M}$ ) than an equal dose of any single-isolated active ingredient, indicating potential synergistic effect and mechanism on Syk.

To further demonstrate that Syk affinitive compounds were the important active ingredients in PLE, the effects of these compounds (RosS, Vic-2 and RosA) and their mixture (Mix) on allergic airway inflammation were evaluated in this study. A crucial molecular mechanism of asthma is Th2 (type 2) inflammation, characterized by increased secretion of type 2 cytokines (such as IL-4), IgEtriggered hypersensitivity reactions and activation of effector cells (mast cells, eosinophils and basophils). ${ }^{28} \mathrm{Syk}$ affinitive compounds, either individually or in combination as in Mix, significantly alleviated allergic inflammation in a mouse model of allergic asthma, ${ }^{29}$ by reducing lung tissue inflammatory histological injuries, inhibiting inflammatory cells recruitment, and decreasing inflammatory cytokines and immunoglobulin secretion. OVAinduced human $\mathrm{PBMCs}^{30}$ and DNP-IgE/BSA-stimulated RBL-2H3 cell ${ }^{31}$ inflammatory responses were also suppressed. Interestingly, a stronger effect was observed with the Mix treatment than with individual Syk affinitive compounds, implying that PLE might exert its antiinflammatory effect via synergistic actions of its Syk affinitive components.

Accordingly, we also studied potential mechanisms of PLE here. Syk plays a key role in mediating allergic airway responses through triggering complex signaling pathways including $\mathrm{PKC}, \mathrm{NF}-\mathrm{\kappa B}$ and $\mathrm{CPLA}_{2}$ and then producing a great quantity of inflammatory mediators. ${ }^{21,32}$ The present results showed that the expression of Syk and p-Syk was significantly suppressed both in vivo and in vitro after RosS, Vic-2, RosA and Mix treatment, indicating decreased Syk protein level and inhibited ability to phosphorylate its downstream proteins. Similarly, the expression and phosphorylation of PKC, $\mathrm{NF}-\mathrm{\kappa B}$ and $\mathrm{CPLA}_{2}$ were reduced upon treatment with these compounds. This suggested that the antiinflammatory effects of Syk affinity compounds in PLE were associated with the inhibition of Syk signaling pathway. Importantly, a synergistic effect was also observed with the Mix treatment, which resulted in further decrease in the expression and phosphorylation levels of these proteins.

Furthermore, by co-treating Mix with Syk inhibitor in DNP-IgE/BSA-stimulated RBL-2H3 cells, an additive inhibition of Syk, PKC, NF- $\mathrm{kB}$ and $\mathrm{cPLA}_{2}$ expression and phosphorylation was exhibited, while NF- $\kappa B$ and cPLA $_{2}$ inhibitors did not affect the expression of Syk and p-Syk, which resulted from the fact that Syk was the upstream factor of NF-kB and $\mathrm{cPLA}_{2} \cdot{ }^{33,34}$ But the relationship between Syk and PKC is still controversial. Some suggested that Syk seemed to be the downstream of PKCmediated in endothelial cell migration, ${ }^{35}$ whereas others reported that Syk was able to activate PKC/NF- $\mathrm{\kappa B}$ signaling pathway for the release of IL-1 $\beta$ in primary human monocytes. ${ }^{36}$ In the present work, the result of PKC inhibitor co-treating with Mix suggested a bidirectional interaction between Syk and PKC with Mix treatment. Taken together, Syk affinitive compounds exerted their antiallergic inflammation effects partly by targeting on Syk, and by modulating its downstream PKC, NF- $\kappa B$ and cPLA $_{2}$.

\section{Conclusion}

Syk affinitive compounds in PLE, extracted and identified by Syk-conjugated beads coupled with LC-MS/MS, may represent the potential major active components that exert a synergistic effect on reducing allergic inflammation. In addition, the potential mechanisms of PLE on alleviating allergic airway inflammation can be exerted partly through the synergistic targeting on Syk and its downstream inflammatory pathway constituents. The results of this study provide a method to screen for active components from plant extract or TCM, and to study their pharmacodynamic properties and mechanisms, especially for 
illustrating the multiple active ingredients targeting on one or more targets.

\section{Abbreviations}

BALF, bronchoalveolar lavage fluid; $\beta$-Hex, $\beta$ hexosaminidase; cPLA2, cytosolic phospholipase A2; Dex, dexamethasone sodium phosphate; ELISA, enzymelinked immunosorbent assay; FceRI, Fc receptors of IgE; $\mathrm{H} \& \mathrm{E}$, hematoxylin-eosin; IFN- $\gamma$, interferon- $\gamma$; Ig, immunoglobulin; IL, interleukin; Mix, a mixture of RosS, Vic-2 and RosA was prepared in accordance with their ratio in Syk-conjugated beads bound fraction; MOD, mean integrated optical density; NF- $\kappa \mathrm{B}$, nuclear factor- $\kappa \mathrm{B}$; OVA, ovalbumin; PBMC, peripheral blood mononuclear cell; PLE, Perilla leaves extract; PKC, protein kinase C; RBL2H3, rat basophilic leukemia-2H3; RosA, rosmarinic acid; RosS, roseoside; SEM, mean \pm standard error; Syk, spleen tyrosine kinase; TCM, traditional Chinese medicine; TNF$\alpha$, tumor necrosis factor- $\alpha$; Vic-2, vicenin-2; WB, Western blotting.

\section{Data Sharing Statement}

The data that support the findings of this study are available from the corresponding author upon reasonable request.

\section{Ethics Approval and Consent to Participate}

All animal experiments were approved from The Animal Care \& Welfare Committee Institute of Meteria Medica, CAMS \& PUMC (Permission number: 00000484), and performed in accordance with the guidelines (Standard Operating Procedure for Animal Experimental Center, Institute of Materia Medica, CAMS \& PUMC) and conformed to internationally accepted ethical standards. The human study had full ethical approval from the Institutional Ethics Committee of Clinical laboratory, Beijing Friendship Hospital (Permission number: BFHCC20160110). Consent was received from the study participants and that the study was conducted in line with the guidelines outlined in the Declaration of Helsinki.

\section{Acknowledgment}

We acknowledge Clinical Laboratory Center of Beijing Friendship Hospital for the provision of healthy volunteers' blood samples.

\section{Author Contributions}

HY performed most experiments, analyzed the data, and wrote portions of the paper draft. WS organized the healthy volunteers and collected the blood samples. PM, CSY, YNF, SYL, JQY, JYB, ZQZ, XYL participated in some experiments. MBL and $\mathrm{QH}$ designed experiments, analyzed the data, and wrote the paper. MBL oversaw the overall execution of the projects and gave final approval of the version to be submitted. All authors contributed to data analysis, drafting, or revising the article, have agreed on the journal to which the article will be submitted, gave final approval of the version to be published, and agree to be accountable for all aspects of the work.

\section{Funding}

This work was financially supported by the National Natural Science Foundation of China (Grant No. 81473398, 81973539 and 81803810), the Beijing Natural Science Foundation Program (Grant no. 7182116), the CAMS Initiative for Innovative Medicine (Grant no. 2016I2M-2-006), the Drug Innovation Major Project of China (Grant no. 2018ZX09711001-003-001), the PUMC Graduate Innovation Fund (Grant no. 2019-1007-14), and the Funds of State Key Laboratory of Bioactive Substance and Function of Natural Medicines of China (Grant No. GTZK201807). The funders had no role in study design, data collection and analysis, decision to publish, or preparation of the manuscript.

\section{Disclosure}

The authors report no conflicts of interest concerning this work.

\section{References}

1. Vuolo F, Abreu SC, Michels M, et al. Cannabidiol reduces airway inflammation and fibrosis in experimental allergic asthma. Eur J Pharmacol. 2018;843:251-259. doi:10.1016/j.ejphar.2018.11.029

2. Du H, Wang Y, Shi Y, et al. Effect of traditional Chinese medicine on inflammatory mediators in pediatric asthma. Mediators Inflamm. 2016;2016:5143703. doi:10.1155/2016/5143703

3. Ahmed HM. Ethnomedicinal, phytochemical and pharmacological investigations of Perilla frutescens (L.) Britt. Molecules. 2018;24 (1):102. doi:10.3390/molecules24010102

4. Chen ML, Wu CH, Hung LS, Lin BF. Ethanol extract of Perilla frutescens suppresses allergen-specific Th2 responses and alleviates airway inflammation and hyperreactivity in ovalbumin-sensitized murine model of asthma. Evid Based Complement Alternat Med. 2015;2015:324265.

5. Chen Y, Chen Z, Wang Y. Immobilized magnetic beads-based multi-target affinity selection coupled with HPLC-MS for screening active compounds from traditional Chinese medicine and natural products. Methods Mol Biol. 2015;1286:121-129. 
6. Hou Y, Cheng B, Zhou M, et al. Searching for synergistic bronchodilators and novel therapeutic regimens for chronic lung diseases from a traditional Chinese medicine, Qingfei Xiaoyan Wan. PLoS One. 2014;9(11):e113104. doi:10.1371/journal.pone.0113104

7. Zhou X, Seto SW, Chang D, et al. Synergistic effects of Chinese herbal medicine: a comprehensive review of methodology and current research. Front Pharmacol. 2016;7:201. doi:10.3389/ fphar.2016.00201

8. Liu J, Liu J, Shen F, et al. Systems pharmacology analysis of synergy of TCM: an example using saffron formula. Sci Rep. 2018;8(1):380. doi:10.1038/s41598-017-18764-2

9. Kubo M. Mast cells and basophils in allergic inflammation. Curr Opin Immunol. 2018;54:74-79. doi:10.1016/j.coi.2018.06.006

10. Siveen KS, Prabhu KS, Achkar IW, et al. Role of non receptor tyrosine kinases in hematological malignances and its targeting by natural products. Mol Cancer. 2018;17(1):31.

11. Dhakal H, Yang EJ, Lee $\mathrm{S}$, et al. Avenanthramide $\mathrm{C}$ from germinated oats exhibits anti-allergic inflammatory effects in mast cells. Sci Rep. 2019;9(1):6884. doi:10.1038/s41598-019-43412-2

12. Ramis I, Otal R, Carreno C, et al. A novel inhaled Syk inhibitor blocks mast cell degranulation and early asthmatic response. Pharmacol Res. 2015;99:116-124. doi:10.1016/j.phrs.2015.05.011

13. Travers T, Kanagy WK, Mansbach RA, et al. Combinatorial diversity of Syk recruitment driven by its multivalent engagement with FcepsilonRIgamma. Mol Biol Cell. 2019;30(17):2331-2347. doi:10.1091/mbc.E18-11-0722

14. Kim E, Son YJ, Yang Y, et al. 1-(2,3-dibenzimidazol-2-ylpropyl)2-methoxybenzene is a Syk inhibitor with anti-inflammatory properties. Molecules. 2016;21(4):508. doi:10.3390/molecules2104 0508

15. Shin D, Park SH, Choi YJ, et al. Dietary compound kaempferol inhibits airway thickening induced by allergic reaction in a bovine serum albumin-induced model of asthma. Int J Mol Sci. 2015;16 (12):29980-29995. doi:10.3390/ijms161226218

16. Carl P, Ramos II, Segundo MA, Schneider RJ. Antibody conjugation to carboxyl-modified microspheres through N-hydroxysuccinimide chemistry for automated immunoassay applications: a general procedure. PLoS One. 2019;14(6):e0218686. doi:10.1371/journal. pone. 0218686

17. Tao Y, Chen Z, Zhang Y, Wang Y, Cheng Y. Immobilized magnetic beads based multi-target affinity selection coupled with high performance liquid chromatography-mass spectrometry for screening antidiabetic compounds from a Chinese medicine "Tang-Zhi-Qing". $J$ Pharm Biomed Anal. 2013;78-79:190-201. doi:10.1016/j. jpba.2013.02.024

18. Lim HJ, Woo KW, Lee KR, Lee SK, Kim HP. Inhibition of proinflammatory cytokine generation in lung inflammation by the leaves of Perilla frutescens and Its Constituents. Biomol Ther (Seoul). 2014;22 (1):62-67. doi:10.4062/biomolther.2013.088

19. Jun HI, Kim BT, Song GS, Kim YS. Structural characterization of phenolic antioxidants from purple perilla (Perilla frutescens var. acuta) leaves. Food Chem. 2014;148:367-372. doi:10.1016/j. foodchem.2013.10.028

20. Hwang YH, Hong SG, Mun SK, et al. The protective effects of astaxanthin on the OVA-induced asthma mice model. Molecules. 2017;22(11):2019. doi:10.3390/molecules22112019

21. Fu L, Guan J, Zhang Y, et al. Tulobuterol patch alleviates allergic asthmic inflammation by blockade of Syk and NF- $\mathrm{BB}$ activation in mice. Oncotarget. 2018;9(15):12154-12163. doi:10.18632/oncotar get. 24348
22. Hwang YH, Kim SJ, Kim H, Yee ST. The protective effects of 2,3,5,4'-tetrahydroxystilbene-2-O-beta-d-glucoside in the OVAinduced asthma mice model. Int J Mol Sci. 2018;19(12):4013. doi:10.3390/ijms19124013

23. Tian K, Shao M, Wang Y, Guan J, Zhou S. Boosting compound-protein interaction prediction by deep learning. Methods. 2016;110:64-72. doi:10.1016/j.ymeth.2016.06.024

24. Wang H, Zhao X, Wang S, et al. Fabrication of enzyme-immobilized halloysite nanotubes for affinity enrichment of lipase inhibitors from complex mixtures. J Chromatogr A. 2015;1392:20-27. doi:10.1016/j. chroma.2015.03.002

25. Ciesla L, Moaddel R. Comparison of analytical techniques for the identification of bioactive compounds from natural products. Nat Prod Rep. 2016;33(10):1131-1145. doi:10.1039/C6NP00016A

26. Hassan N, Ali A, Withycombe C, et al. TET-2 up-regulation is associated with the anti-inflammatory action of vicenin-2. Cytokine. 2018;108:37-42. doi:10.1016/j.cyto.2018.03.016

27. Liang $\mathrm{Z}, \mathrm{Xu} \mathrm{Y}$, Wen $\mathrm{X}$, et al. Rosmarinic acid attenuates airway inflammation and hyperresponsiveness in a Murine Model of Asthma. Molecules. 2016;21(6):769. doi:10.3390/ molecules 21060769

28. Fahy JV. Type 2 inflammation in asthma-present in most, absent in many. Nat Rev Immunol. 2015;15(1):57-65. doi:10.1038/nri3786

29. Wang J, Li FS, Pang NN, et al. Inhibition of asthma in OVA sensitized mice model by a traditional uygur herb nepeta bracteata benth. Evid Based Complement Alternat Med. 2016;2016:5769897.

30. Nakazato J, Kishida M, Kuroiwa R, et al. Serum levels of Th2 chemokines, CCL17, CCL22, and CCL27, were the important markers of severity in infantile atopic dermatitis. Pediatr Allergy Immunol. 2008;19(7):605-613.

31. Tan JW, Israf DA, Harith $\mathrm{HH}$, et al. Anti-allergic activity of 2,4,6-trihydroxy-3-geranylacetophenone (tHGA) via attenuation of IgE-mediated mast cell activation and inhibition of passive systemic anaphylaxis. Toxicol Appl Pharmacol. 2017;319:47-58. doi:10.1016/ j.taap.2017.02.002

32. Yoo J-M, Park KI, Yang J-H, et al. Anti-allergic actions of F-PASA, a novel herbal cocktail, in IgE/antigen-mediated allergic responses in RBL-2H3 cells and passive cutaneous anaphylaxis in mice. Phytomedicine. 2019;55:229-237. doi:10.1016/j. phymed.2018.06.034

33. Fan $\mathrm{Y}$, Zhang $\mathrm{Z}$, Yao $\mathrm{C}$, et al. Amurensin $\mathrm{H}$, a derivative from resveratrol, ameliorates lipopolysaccharide/cigarette smoke-induced

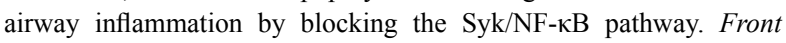
Pharmacol. 2019;10:1157. doi:10.3389/fphar.2019.01157

34. Li X, Lu Y, Jin Y, et al. Curcumin inhibits the activation of immunoglobulin e-mediated mast cells and passive systemic anaphylaxis in mice by reducing serum eicosanoid and histamine levels. Biomol Ther. 2014;22(1):27-34. doi:10.4062/biomolther.2013.092

35. Wen H-C, Huo YN, Chou C-M, Lee W-S. PMA inhibits endothelial cell migration through activating the $\mathrm{PKC}-\delta / \mathrm{Syk} / \mathrm{NF}-\kappa \mathrm{B}-\mathrm{mediated}$ up-regulation of Thy-1. Sci Rep. 2018;8(1):16247. doi:10.1038/ s41598-018-34548-8

36. Pandori WJ, Lima TS, Mallya S, et al. Toxoplasma gondii activates a Syk-CARD9-NF-kappaB signaling axis and gasdermin D-independent release of IL-1beta during infection of primary human monocytes. PLoS Pathog. 2019;15(8):e1007923. doi:10.1371/journal.ppat.1007923 


\section{Publish your work in this journal}

The Journal of Inflammation Research is an international, peerreviewed open-access journal that welcomes laboratory and clinical findings on the molecular basis, cell biology and pharmacology of inflammation including original research, reviews, symposium reports, hypothesis formation and commentaries on: acute/chronic inflammation; mediators of inflammation; cellular processes; molecular mechanisms; pharmacology and novel anti-inflammatory drugs; clinical conditions involving inflammation. The manuscript management system is completely online and includes a very quick and fair peerreview system. Visit http://www.dovepress.com/testimonials.php to read real quotes from published authors.

Submit your manuscript here: https://www.dovepress.com/journal-of-inflammation-research-journal 